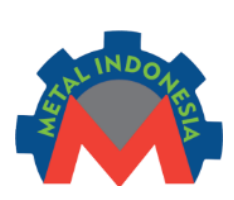

JMI Vol. 39 No. 1 Juni 2017

METAL INDONESIA

Journal homepage:

http://www.jurnalmetal.or.id/index.php/jmi

p-issn : $0126-3463$

e-issn : $2548-673 \mathrm{X}$

\title{
PENGARUH PROSES POWDER NITRIDING TERHADAP PERUBAHAN KEKERASAN DAN TEBAL LAPISAN DIFUSI PADA PAHAT BUBUT HIGH SPEED STEEL
}

\section{EFFECTS OF POWDER NITRIDING PROCESS TO HARDNESS AND DIFFUSION LAYER DEPTH OF HIGH SPEED STEEL}

\author{
Sri Rahayu ${ }^{1}$; Ngainun Setiawan ${ }^{2}$; Shinta Virdhian ${ }^{2 *}$; Endi Suhendi ${ }^{{ }^{*}}$ \\ ${ }^{1}$ Jurusan Pendidikan Fisika, Fakultas Pendidikan Matematika dan Ilmu Pengetahuan Alam, \\ Universitas Pendidikan Indonesia (UPI), Jl. Dr. Setiabudhi 229, Bandung 40154, Indonesia \\ ${ }^{2}$ Balai Besar Logam dan Mesin (BBLM) Jl. Sangkuriang No.12, Bandung 40135, Indonesia \\ email: Sri.rahayu34@student.upi.edu
}

\begin{abstract}
Abstrak
Telah dilakukan penelitian mengenai proses powder nitriding dengan menambahkan unsur nitrogen kedalam permukaan baja dengan menggunakan media padat berupa serbuk nitrida. Proses powder nitriding ini menggunakan temperatur nitridasi $560^{\circ} \mathrm{C}$ dan $600^{\circ} \mathrm{C}$ dengan holding time 1 dan 3 jam. Media nitridasi yang digunakan adalah urea dan cangkang kerang. Dari hasil pengujian menunjukkan bahwa : kekerasan permukaan tertinggi diperoleh pada suhu $560^{\circ} \mathrm{C}$ dengan holding time 1 jam yaitu sebesar 876,94 HV atau meningkat sebesar 22\% dari raw material (720 HV). Hasil pengamatan struktur mikro kedalaman lapisan difusi tertinggi yang diperoleh yaitu sebesar $21 \mu \mathrm{m}$ untuk suhu $560^{\circ} \mathrm{C}$ dengan holding time 3 jam. Pengujian EDS menunjukkan kandungan nitrogen hasil nitridasi pada suhu $560^{\circ} \mathrm{C}$ dengan holding time 1 jam yaitu sebesar $3,08 \%$ berat atau $11,08 \%$ atom.
\end{abstract}

Kata kunci : Powder Nitriding, Urea, Cangkang kerang, Kekerasaan, Kedalaman lapisan difusi

\begin{abstract}
Research on powder nitriding was done by adding nitrogen elements to the steel surface using a solid medium of nitride powder. The powder nitriding processed by carried out temperatures $560^{\circ} \mathrm{C}$ and $600^{\circ} \mathrm{C}$ with 1 hour and 3 hours holding time. Nitriding medium consisted of urea and shellfish. Result showed that the highest surface hardness that obtained at temperature $560^{\circ} \mathrm{C}$ with 1 hour holding time was 876,94 HV or increased $22 \%$ from raw material (720 HV). Micro structure observation showed the depth of the highest diffusion layer was $21 \mu \mathrm{m}$ for the temperature $560^{\circ} \mathrm{C}$ with holding time 3 hours. EDS test result also showed that nitrogen content at $560^{\circ} \mathrm{C}$ with 1 hour holding time is $3.08 \%$ wt or $11.08 \%$ at.
\end{abstract}

Keywords: Powder Nitriding, Urea, Shellfish, Hardness, Depth of nitrogen diffusion layer

\section{PENDAHULUAN}

Pahat merupakan alat potong yang memegang peran penting dalam industri manufaktur terutama pada proses pembuatan suatu komponen perkakas/mesin. Adapun beberapa kriteria yang harus dimiliki pahat diantaranya: harus lebih keras dibanding benda kerja, tahan sifat mekanis, dan tahan aus. Material pahat terdiri dari beberapa jenis, diantaranya: baja karbon, HSS (High Speed Steel), paduan cor nonferro, karbida, keramik, CBN (Cubic Boron Nitrides), dan intan. Material pahat yang paling umum digunakan adalah tungsten carbida, namun bahan tungsten carbida sangat mahal harganya sehingga banyak penelitian yang mengembangkan jenis material pahat yang baru dan relatif murah, salah satunya adalah baja kecepatan tinggi (High Speed Steel). Pahat HSS memiliki keunggulan dibandingkan dengan bahan pahat yang lain yaitu sifat keuletannya yang relatif baik dan apabila telah aus pahat HSS masih dapat diasah sehingga mata potongnya menjadi tajam kembali. 
Salah satu upaya meningkatkan performance dari material HSS adalah dengan ternik surface treatment. Teknik surface treatment merupakan teknik untuk mengubah sifat permukaan dengan cara menambahkan unsur lain atau mengubah komposisi kimia pada material logam/baja. Surface treatment dapat dilakukan dengan cara nitridasi, karburisasi, dan karbonitridasi.

Proses nitridasi merupakan suatu proses pengerasan permukaan yang dilakukan dengan cara mendifusikan atom nitrogen ke permukaan baja yang berada dalam fasa ferit pada temperatur $500^{\circ} \mathrm{C}-590^{\circ} \mathrm{C}$. Pada temperatur ini tidak terjadi perubahan fasa selama pendinginan, sehingga dapat menghindari terjadinya distorsi dan memberikan kontrol dimensi yang lebih baik. Reaksi antara nitrogen dan besi menyebabkan pembentukan nitrida pada permukaan sehingga mengakibatkan peningkatan kekerasan pada permukaan baja. ${ }^{\left[{ }^{8]}\right.}$

Proses powder nitriding yaitu proses nitidasi yang menggunakan serbuk nitrida sebagai media nitridasinya. Serbuk nitrida yang dapat digunakan adalah Urea $\left(\mathrm{CO}\left(\mathrm{NH}_{2}\right)_{2}\right)$. Urea mampu menyediakan nitrogen untuk didifusikan ke dalam permukaan baja. Pada temperatur nitridasi, urea akan terurai sehingga dapat menghasilkan atom nitrogen yang berdifusi kedalam permukaan besi, menurut reaksi :

$$
\mathrm{CO}\left(\mathrm{NH}_{2}\right)_{2} \longrightarrow \mathrm{NH}_{3}+\mathrm{HNCO}^{[1]}
$$

Proses ini menghasilkan residu cyanic acid (HNCO).

Untuk dapat digunakan dalam proses nitridasi, nitrogen harus dalam keadaan monoatomik. Dalam prakteknya, gas $\mathrm{N}$ yang monoatomik dapat diperoleh dari pemanasan gas amoniak $\left(\mathrm{NH}_{3}\right)$. Pada temperatur nitridasi gas amoniak akan terurai sebagai berikut:

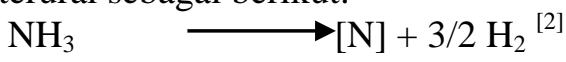

Nitrogen yang terbentuk akan bereaksi dengan Fe membentuk nitrida besi yang keras. Karena sifat nitrida yang keras, lapisan nitridasi yang terbentuk tidak boleh terlalu tebal (sangat getas).

Pada kondisi tertentu, atom-atom nitrogen yang berdifusi akan bereaksi dengan atom-atom besi membentuk senyawa nitrida besi $\mathrm{FeN}$ seperti $\mathrm{Fe}_{2} \mathrm{~N}, \mathrm{Fe}_{3} \mathrm{~N}$, dan $\mathrm{Fe}_{4} \mathrm{~N}$ yang memiliki sifat keras dan stabil pada temperatur tinggi. Ketika mencapai temperatur nitridasi, nitrogen akan terlarut dalam besi dengan kelarutan maksimum $0,1 \%$ massa. Ketika lebih besar dari $0,1 \%$ maka akan membentuk senyawa nitrida $\gamma^{\prime}\left(\mathrm{Fe}_{4} \mathrm{~N}\right)$. Jika kelarutan nitrogen pada besi melebihi $6 \%$, nitrida $\gamma^{\prime}\left(\mathrm{Fe}_{4} \mathrm{~N}\right)$ akan berubah menjadi $\varepsilon\left(\mathrm{Fe}_{2}\right.$ $\left.{ }_{3 \mathrm{~N}}\right)$. Pada temperatur $500^{\circ} \mathrm{C}$ dengan kadar nitrogen lebih dari $11 \%$ maka nitrida $\xi\left(\mathrm{Fe}_{2} \mathrm{~N}\right)$ akan segera terbentuk dan diatas $650^{\circ} \mathrm{C} \mathrm{Fe}{ }_{4} \mathrm{~N}$ akan terurai. Secara fisik nitrida $\gamma^{\prime}$ dan $\varepsilon$ pada permukaan baja terlihat sebagai lapisan putih (white layer). ${ }^{[1]}$

Beberapa penelitian tentang pengerasan permukaan HSS banyak dilakukan dengan pelapisan. Ibrahim pada tahun 2004 melakukan Penelitian deposisi lapisan tipis TiN pada substrat HSS dengan teknik sputtering, berhasil meningkatkan kekerasan sebesar $61.6 \%$ dan umur pemakaiannya meningkat $17 \%$. Supriyanto pada tahun 2005 melakukan Penelitian deposisi lapisan tipis TiN/AlN pada pahat bubut HSS dengan teknik sputtering,berhasil meningkatkan kekerasan sebesar $107 \%$ dan umur pahat meningkat 80 100\%. Sunarto pada tahun 2010 melakukan penelitian deposisi lapisan tipis plasma/ion nitrogen pada pahat bubutHSS dengan teknik plasma nitriding, berhasil meningkatkan kekerasan dari 402 VHN menjadi 1918 VHN atau kekerasannya meningkat sebesar $477 \%$ dan meningkatkan ketahanan aus sebesar $64 \%$.

Namun dari beberapa metode nitridasi seperti nitridasi plasma, nitridasi gas, nitridasi cair/larutan dan implementasi ion memiliki kelemahan, diantaranya membutuhkan proses yang rumit, menghasilkan limbah berbahaya dan membutuhkan biaya yang sangat besar untuk menghasilkan tebal lapisan nitrida yang diinginkan.

Berdasarkan latar belakang diatas, penulis mencoba untuk melakukan penelitian tentang proses nitridasi padat menggunakan serbuk urea $\left(\mathrm{CO}\left(\mathrm{NH}_{2}\right)_{2}\right)$ pada pahat bubut HSS berdasarkan temperatur dan holding time yang telah ditentukan. Hal ini bertujuan untuk melihat dan mengetahui seberapa besar pengaruh proses nitridasi dengan menggunakan urea $\left(\mathrm{CO}\left(\mathrm{NH}_{2}\right)_{2}\right)$ mampu meningkatkan nilai kekerasan yang dihasilkan setelah spesimen uji mengalami proses nitridasi. Penggunaan urea dipilih karena 
mampu menyediakan nitrogen untuk didifusikan ke dalam permukaan baja serta mudah didapat dipasaran dengan harga yang relatif murah. Pada penelitian kali ini ditambahkan cangkang kerang sebagai bahan untuk mempercepat pembentukan gas nitrogen dalam proses powder nitriding.

Penelitian ini bertujuan untuk mengetahui pengaruh dari temperatur dan holding time terhadap perubahan nilai kekerasan permukaan dan kedalaman difusi nitrogen setelah dilakukan proses powder nitriding.

\section{METODE PENELITIAN}

Metode penelitian yang digunakan pada penelitian ini adalah metode eksperimen. Pada penelitian ini dilakukan proses powder nitriding pada pahat bubut HSS. Selanjutnya material yang telah di nitriding tersebut dilakukan pengujian yang meliputi uji kekerasan, uji struktur mikro (kedalaman difusi nitrogen) dan uji $E D S$.

\section{Spesimen uji dan media nitridasi}

Pada penelitian ini spesimen uji yang digunakan adalah pahat bubut HSS yang berbentuk batangan yang kemudian dipotong dengan ukuran dimensi $12 \mathrm{~mm} \times 12 \mathrm{~mm}$ x 6 $\mathrm{mm}$. Sedangkan media nitridasi yang digunakan yaitu serbuk urea $\left(\mathrm{CO}\left(\mathrm{NH}_{2}\right)_{2}\right)$ sebagai penghasil unsur nitrogen murni dan bubuk cangkang kerang sebagai bahan untuk mempercepat pembentukan gas nitrogen dalam proses powder nitriding.

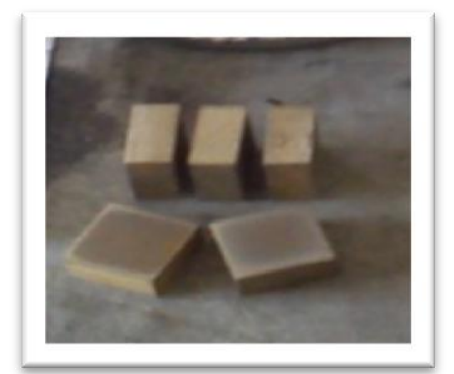

Gambar 1. Spesimen uji

\section{Powder Nitriding}

Proses nitridasi dilakukan di Laboratorium Fabrikasi dan Heat Treatment Politeknik Manufaktur Bandung. Langkah awal yang dilakukan sebelum proses nitridasi adalah memasukkan campuran media nitridasi dan specimen uji kedalam tabung nitridasi.

METAL INDONESIA Vol. 39 No. 1 Juni 2017 (20-26)

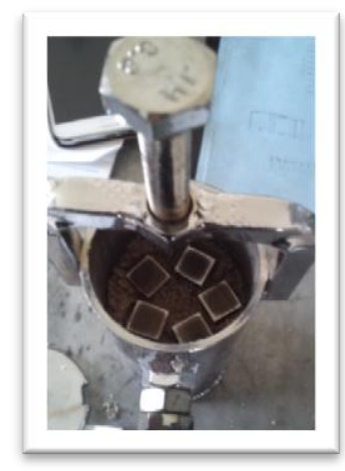

Gambar 2. Posisi spesimen didalam tabung nitridasi

Selanjutnya tabung nitridasi dipanaskan didalam tungku pemanas pada temperatur yang telah ditentukan $\left(560^{\circ} \mathrm{C}\right.$ dan $\left.600^{\circ} \mathrm{C}\right)$ dengan holding time selama 2 jam dan 3 jam.

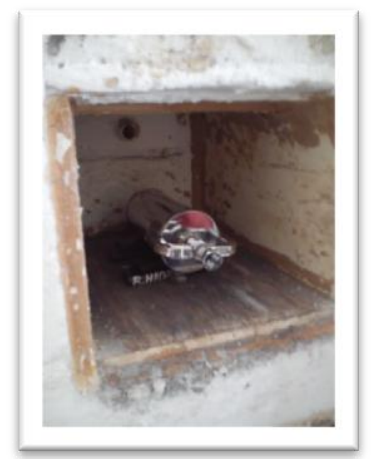

Gambar 3. Tabung nitridasi didalam tungku pemanas

Kemudian tabung dikeluarkan dari tungku dan didinginkan secara perlahan dalam udara bebas.

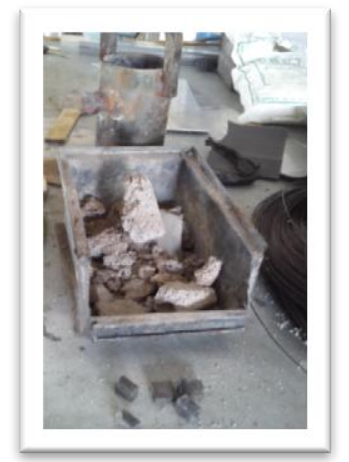

Gambar 4. Spesimen setelah dinitridasi

\section{Karakterisasi}

Pengujian kekerasan dilakukan untuk mengetahui distribusi kekerasan pada setiap spesimen. Pengujian dilakukan dengan metode mikro vikers. Setelah diampelas, dipoles dan dietsa, spesimen tersebut di uji dengan 
pengujian beban 300 gf dan lama pembebanan selama 15 detik. Kemudian hasilnya dilihat dengan menggunakan microscope untuk mengukur panjang diagonal bekas indensi yang berbentuk layang-layang. Setelah mendapatkan panjang diagonal dari kedua diagonal layanglayang maka nilai uji kekerasan dapat dihitung dengan menggunakan persamaaan :

$$
H_{v}=1,8544 \frac{F}{d^{2}}
$$

Pada penelitian ini juga dialakukan pengujian komposisi kimia untuk raw material menggunakan spectrometer OES (PMI MasterPro, OXFORD), pengujian struktur mikro dan pengujian EDS. Pengujian struktur mikro dilakukan untuk melihat perubahan fasa dan kedalaman difusi nitrogen yang terjadi setelah dilakukan proses nitridasi. Untuk kedalaman lapisan nitridasi ditentukan dengan mengukur jarak dari permukaan sampai pada suatu daerah yang kontras antara permukaan dan inti pada sampel setelah dinitridasi yang diperoleh dari hasil foto mikrografi dengan perbesaran 500x. Sedangkan pengujian EDS dilakukan untuk mengetahui kandungan nitrogen yang terdeposisi pada lapisan nitridasi.

\section{HASIL DAN PEMBAHASAN}

\section{Uji komposisi}

Hasil pengujian komposisi kimia raw material, dengan persentase berat masing-masing unsur sebagai berikut :

Tabel 1. komposisi kimia raw material

\begin{tabular}{|c|ccccccccc|}
\hline Unsur & $\mathrm{Fe}$ & $\mathrm{C}$ & $\mathrm{Si}$ & $\mathrm{Cr}$ & $\mathrm{Mo}$ & $\mathrm{V}$ & $\mathrm{W}$ & $\mathrm{Mn}$ & $\mathrm{N}$ \\
\hline$\%$ & 89.4 & 0.95 & 1.27 & 4.1 & 0.98 & 0.85 & 1.77 & 0.36 & - \\
\hline
\end{tabular}

Dari tabel 1 terlihat bahwa bahan pahat yang digunakan untuk penelitian ini memiliki spesifikasi mendekati standar AISI M-52. M-52 diklasifikasikan sebagai tipe intermediet high speed steel dengan nilai kekerasan berkisar antara 58-64 HRC. Karena memiliki sifat ketangguhan yang cukup baik, maka material ini dapat digunakan untuk memotong benda kerja dengan kekerasan rendah.

\section{Uji Kekerasan}

Pengujian dilakukan di 5 titik yang berbeda secara vertikal. Berikut data hasil pengujian yang diperoleh, untuk memudahkan analisis maka dibuat grafik hubungan antara nilai kekerasan rata-rata terhadap jarak dari permukaan spesimen sebagai berikut :

Tabel 2. Nilai kekerasan rata-rata

\begin{tabular}{|c|c|c|c|c|}
\hline \multirow{2}{*}{$\begin{array}{c}\text { Jarak dari } \\
\text { permukaan } \\
(\mathrm{mm})\end{array}$} & \multicolumn{3}{|c|}{ Nilai kekerasan rata-rata (HV) } \\
\cline { 2 - 5 } & \multicolumn{2}{|c|}{ Suhu 560 ${ }^{0} \mathrm{C}$} & \multicolumn{2}{c|}{ Suhu 600 ${ }^{0} \mathrm{C}$} \\
\hline 0,010 & 1 Jam & 3 Jam & 1 Jam & 3 Jam \\
\hline 0,015 & 782,748 & 772,16 & 723,95 & 688,42 \\
\hline 0,020 & 744,98 & 697,58 & 681,37 & 623,36 \\
\hline 0,030 & 711,13 & 652,2 & 577,22 & 573,05 \\
\hline 0,040 & 667,15 & 616,12 & 572,82 & 547,98 \\
\hline
\end{tabular}

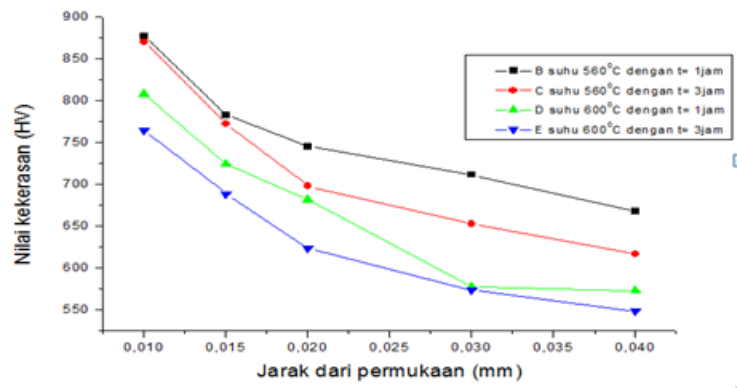

Gambar 5. Grafik nilai kekerasan rata-rata terhadap jarak dari permukaan

Pada tabel 2 dan gambar 5 terlihat bahwa bagian sisi tepi permukaan memiliki nilai kekerasan paling tinggi dan menurun seiring dengan meningkat nya kedalaman dari permukaan baja. Hal ini terjadi karena konsentrasi atom-atom nitrogen yang berdifusi pada permukaan baja akan jauh lebih besar dibandingkan dengan daerah pada kedalaman tertentu dan inti baja. Temperatur dan holding time pada proses nitridasi sangat berpengaruh terhadap nilai kekerasan yang dihasilkan. Hal ini dibuktikan dari variasi distribusi nilai kekerasan pada grafik diatas. Dari grafik, pada temperatur $560^{\circ} \mathrm{C}$ dan holding time 1 jam menghasilkan kekerasan permukaan paling tinggi yaitu $876 \mathrm{HV}$. Pada temperatur $600^{\circ} \mathrm{C}$ nilai kekerasan permukaan menurun menjadi 807 HV. Hal ini disebabkan karena pada temperatur tersebut nitrida besi yang terbentuk terurai kembali yang mengakibatkan kekerasan akan menurun. ${ }^{1-2}$

\section{Uji Struktur Mikro}

Struktur mikro diperoleh dari pemeriksaan metalografi raw material (material sebelum mengalami proses nitridasi) dan spesimen yang telah mengalami proses nitridasi. Hasil struktur 
mikro ditunjukkan pada gambar - gambar berikut ini.

Struktur mikro raw material (material sebelum mengalami proses nitridasi)

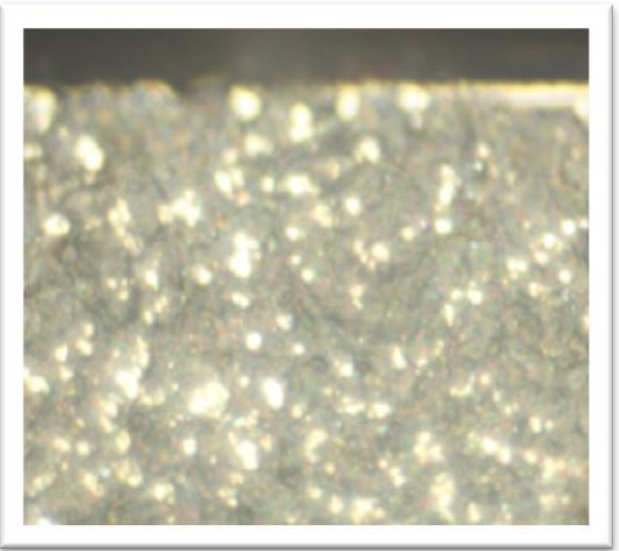

Gambar 6. Struktur mikro raw material

Gambar 6 menunjukan bahwa struktur mikro baja sebelum diberi perlakuan nitridasi terdiri dari fasa martensit yang berbentuk jarum-jarum dan karbida didalam matriks martensit.

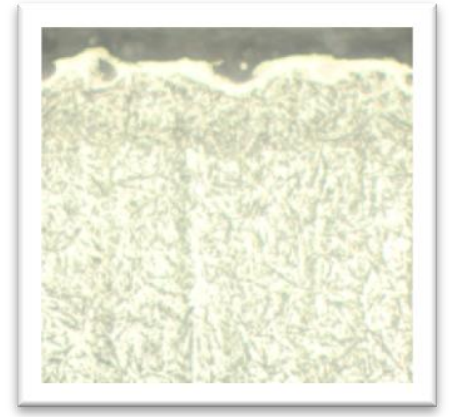

(a)

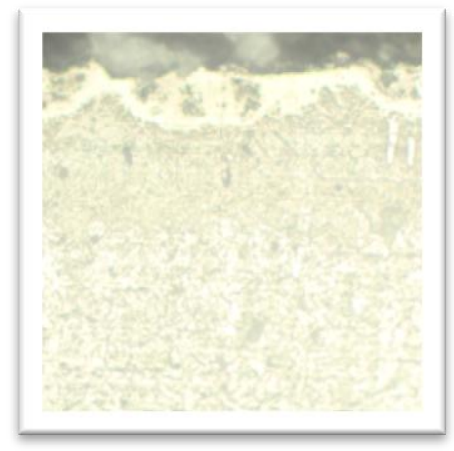

(b)

Gambar 7. Struktur mikro hasil nitridasi dengan suhu $560^{\circ} \mathrm{C}$ (a) $\mathrm{t}=1 \mathrm{jam}$, (b) $\mathrm{t}=3 \mathrm{jam}$

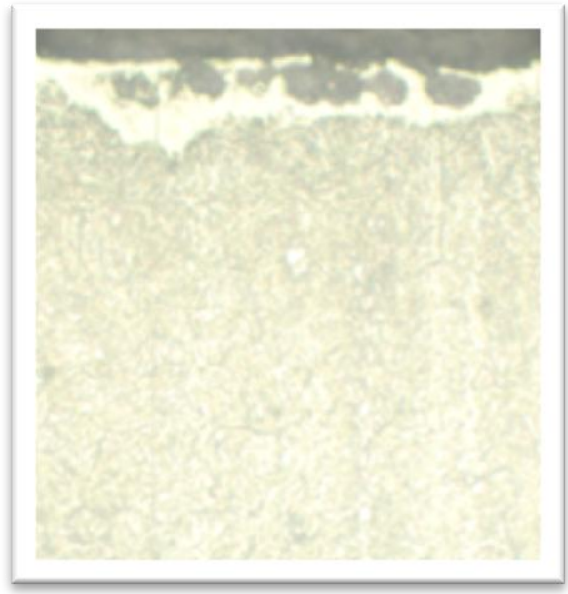

(a)

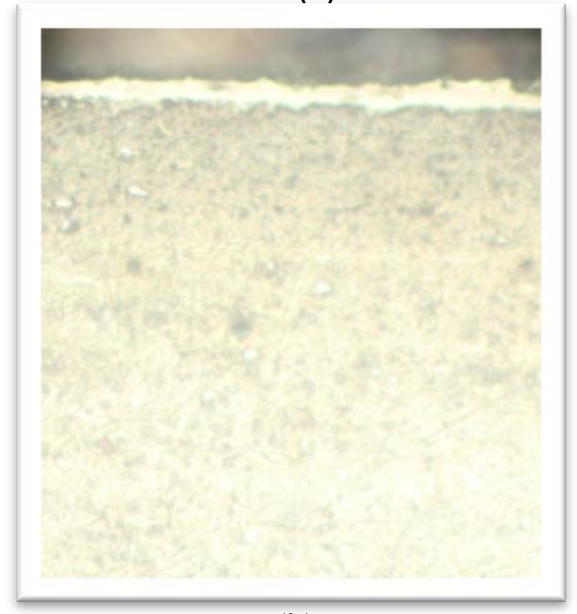

(b)

Gambar 8. Struktur mikro hasil nitridasi dengan suhu $600^{\circ} \mathrm{C}$ (a) $\mathrm{t}=1$ jam, (b) $\mathrm{t}=3$ jam

Gambar 7 dan Gambar 8 merupakan struktur mikro spesimen yang telah dinitridasi yang memperlihatkan adanya lapisan nitrida pada permukaan baja. Lapisan nitrida terbentuk karena atom nitrogen yang berdifusi akan bereaksi dengan atom besi yang terdapat pada baja membentuk senyawa $\mathrm{FeN}$ (seperti $\mathrm{Fe}_{4} \mathrm{~N}$ dan $\mathrm{Fe}_{2} \mathrm{~N}$ ) yang terlihat sebagai lapisan putih (white layer). Selain lapisan putih dipermukaan baja juga terdapat daerah yang berwarna agak gelap, struktur mikro daerah tersebut sama dengan struktur mikro base metal yaitu berupa martensit namun memiliki butir lebih halus dibandingkan dengan base metal. Sehingga kekerasan daerah tersebut menjadi tinggi.

\section{Uji ketebalan lapisan nitridasi}

Pada penelitian ini, hasil pengujian kedalaman lapisan nitridasi yang terbentuk ditentukan berdasarkan kedalaman unsur nitrogen yang 
terintetisi masuk kedalam permukaan spesimen akibat proses nitridasi pada temperatur $560^{\circ} \mathrm{C}$ dan $600^{\circ} \mathrm{C}$ dengan holding time selama 1 jam dan 3 jam. Hasil uji tebal lapisan difusi diperoleh dari hasil foto mikrografi dengan perbesaran 500x dan digambarkan melalui grafik hubungan antara holding time terhadap tebal lapisan difusi sebagai berikut:

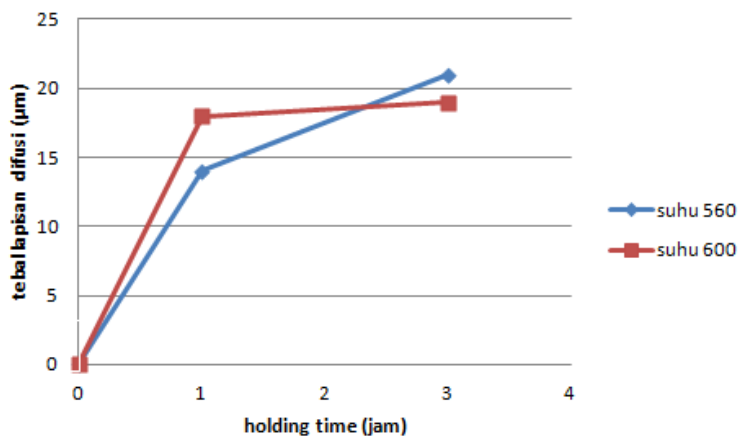

Gambar 9. Grafik holding time tedrhadap tebal lapisan difusi

Gambar 9 menunjukan bahwa kedalaman lapisan difusi yang terbentuk semakin tinggi seiring bertambahnya waktu nitridasi. Hal ini disebabkan oleh karena kemapuan atom nitrogen berdifusi akan lebih besar dengan bertambahnya waktu nitridasi, sehingga atom tersebut dapat bergerak lebih jauh kedalam permukaan baja.

Gambar 9 juga menunjukkan bahwa kedalaman nitridasi semakin tinggi seiring meningkatnya temperatur pemanasan. Hal ini disebabkan semakin tinggi temperatur maka semakin cepat atom-atom nitrogen berdifusi kedalam baja, sehingga atom nitrogen dapat bergerak lebih cepat dan lebih jauh kedalam permukaan baja.

\section{Uji EDS}

Pengujian EDS (Energy Dispersive Spectoscopy) dilakukan di Laboratorium Politeknik Manufaktur Bandung. pengujian EDS dilakukan untuk mengetahui kandungan \% nitrogen pada spot/daerah tertentu di lapisan nitridasi.
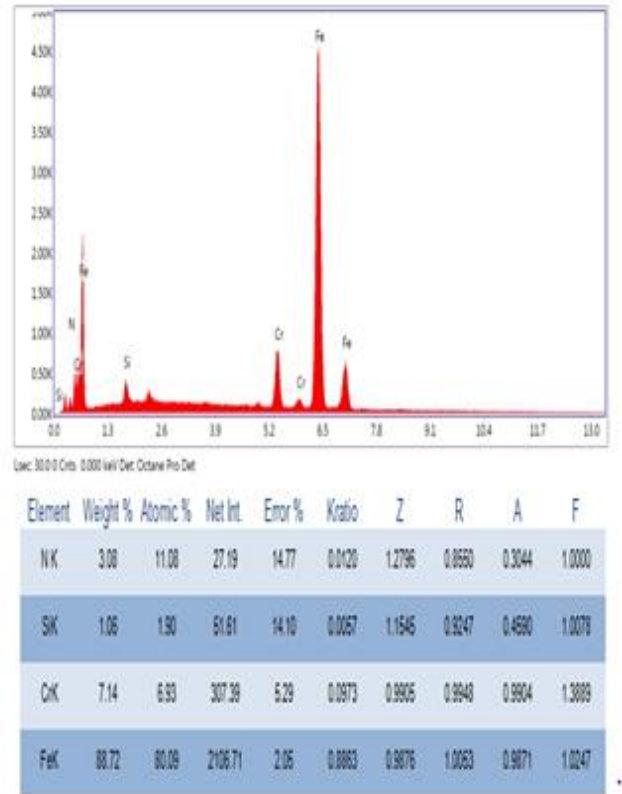

Gambar 10a. Hasil pengujian EDS material HSS proses nitriding dengan suhu $560^{\circ} \mathrm{C}$ selama $1 \mathrm{jam}$.
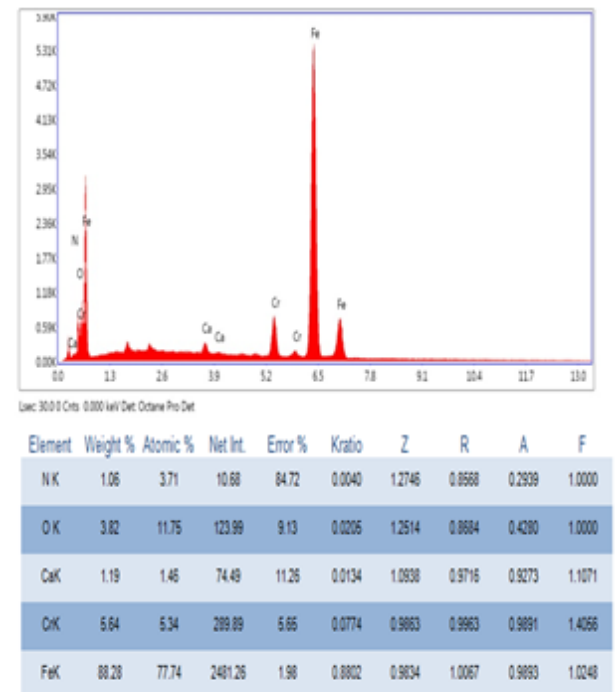

Gambar 10b. Hasil pengujian EDS material HSS proses nitriding dengan suhu $600^{\circ} \mathrm{C}$ selama 3 jam.

Gambar 10a merupakan hasil pengujian EDS dengan variasi suhu $560^{\circ} \mathrm{C}$ selama $1 \mathrm{jam}$, hasil pengujian pada permukaan menunjukan terdapat kandungan unsur nitrogen sebesar 3,08 $\%$ berat atau $11,08 \%$ atom. Gambar $10 \mathrm{~b}$ merupakan hasil pengujian EDS dengan variasi suhu $600^{\circ} \mathrm{C}$ selama 3 jam, hasil pengujian pada permukaan menunjukan terdapat kandungan unsur nitrogen sebesar $1,06 \%$ berat atau 3,71\% atom. Jika dikomparasikan dengan diagram 
FeN, kemungkinan diperoleh senyawa $\mathrm{Fe}_{4} \mathrm{~N}$. Jika dilihat dari kandungan unsur nitrogen yang hanya mencapai $11,08 \%$ atom maka proses nitridasi belum mencapai optimal, karena untuk mencapai optimal seharusnya kandungan unsur nitrogen sekitar $20 \%$ atom sehingga dapat diperoleh senyawa $\mathrm{Fe}_{4} \mathrm{~N}$ yang mempunyai sifat sangat keras.

\section{KESIMPULAN}

Dari penelitian yang telah dilakukan dapat disimpulkan sebagai berikut:

1. Hasil pengujian kekerasan dengan menggunakan mikro vikers hardness menunjukan bahwa proses nitridasi dengan variasi temperatur dan holding time menghasilkan nilai kekerasan permukaan sampel yang berbeda-beda yaitu berkisar 764 HV- 876 HV. Semakin tinggi temperatur dan semakin lama holding time, maka nilai kekerasan semakin menurun.

2. Hasil pengujian struktur mikro dengan menggunakan mikroskop optik menunjukan nilai kedalaman difusi yang berkisar $14 \mu \mathrm{m}$ $21 \mu \mathrm{m}$. Dimana semakin tinggi temperatur dan semakin lama holding time maka kedalaman difusi pun semakin meningkat.

\section{DAFTAR PUSTAKA}

Albertus, B. (2009). Pengaruh Temperatur dan Waktu Proses Nitridasi Terhadap Kekerasan Permukaan FCD 700 Dengan Media Nitridasi Urea. Seminar Nasional Kluster Riset Teknik Mesin 2009.

J.Dosset and G.E. Totten, Fundamentals of Nitriding and Nitrocarburizing, ASM Handbook VOLUME 4A pg. 619-646.

Bakran, Fachmi Hasan . (2011). Pengaruh Nitridasi terhadap Laju Korosi pada Baja KS01. Tugas Akhir Sarjana S-1, Departemen Matematika dan Ilmu Pengetahuan Alam, Program Studi Fisika IPB, Bogor.

Bangun, dkk. (2012). Pengaruh Waktu dan Temperatur Niridasi Plasma Terhadap Kekerasan Bantalan Bola Setelah Dianelling. Seminar Nasional VIII SDM Teknologi Nuklir, 31 Oktober 2012. ISSN : 1978-0176

Ibrahim, AG. (2004). Pengaruh Tebal Potong Terhadap Laju Keausan Pahat Bubut HSS Yang Dilapisi Titanium Nitrida dengan Teknik Sputtering. Tesis, Jurusan Teknik Mesin UGM, Yogyakarta.

Putra, S. (2004). Powder Nitriding pada Baja Paduan Tinggi X165CrMoV12 dengan Media Nitridasi Urea, Tugas Akhir Sarjana S-1, Departemen Teknik Mesin, Program Studi Teknik Material ITB, Bandung .

Sunarto. (2010). Pengaruh Surface Treatment Metoda Plasma Nitriding Terhadap Kekerasan dan Ketahanan Aus Pahat Bubut Bahan Baja Kecepatan Tinggi. Prosiding Seminar Nasional Sains dan Teknologi 2010.

Supriyanto, (2005), Pengaruh Pelapisan TiN dan AlN pada bahan HSS terhadap Kekerasan dan Umur Pahat. Tesis S2, Jurusan Teknik Mesin UGM, Yogyakarta.

Suratman, Rochim. (1994). Panduan Proses Perlakuan Panas, Lembaga Penelitian Institut Teknologi Bandung. 
